\title{
OVERVIEW OF THE TEMPORAL VARIATION OF PM 10 MASS CONCENTRATIONS IN THE TWO MAJOR CITIES IN GREECE: ATHENS AND THESSALONIKI
}

\author{
E. TRIANTAFYLLOU ${ }^{1}$ \\ G. BISKOS ${ }^{1,2, *}$
}

\author{
${ }^{1}$ Department of Environment, University of the Aegean \\ Mytilene 81100, Greece \\ ${ }^{2}$ Faculty of Applied Sciences, Delft University of Technology \\ Delft 2628-BL, The Netherlands
}

Received: $17 / 11 / 11$

Accepted: 15/02/12 *to whom all correspondence should be addressed: e-mail: biskos@aegean.gr; gbiskos@tudelft.nl

\begin{abstract}
Literature reports have indicated that Particulate Matter (PM) concentrations in the atmosphere over the major urban centres of Greece are high compared to other European cities of the same size. The great majority of these reports are based on measurements that have been conducted over a limited amount of time. This study provides an overview of the temporal variation that shows the trends of $\mathrm{PM}_{10}$ concentrations in the two major urban centres of Greece (Athens and Thessaloniki) during the last decade (i.e., from 2001 to 2010). Annual average $\mathrm{PM}_{10}$ concentrations at the urban monitoring stations in Athens range from 32.3 to $62.5 \mu \mathrm{g} \mathrm{m}^{-3}$, and at the suburban stations from 21.5 to $62.9 \mu \mathrm{g}$ $\mathrm{m}^{-3}$. In Thessaloniki the respective values range from 41.7 to $70.8 \mu \mathrm{g} \mathrm{m}^{-3}$ for the urban stations, and from 23.4 to $51.5 \mathrm{\mu g} \mathrm{m}^{-3}$ for the suburban. The highest and the lowest monthly average $\mathrm{PM}_{10}$ concentrations at the urban stations in Athens are observed during the autumn/winter and the summer months, respectively. For the suburban stations the highest values are observed during the spring and the lowest during the winter. In Thessaloniki, autumn exhibits the highest and summer the lowest $\mathrm{PM}_{10}$ values both for the urban and the suburban stations.
\end{abstract}

KEYWORDS: Air Pollution, Particulate Matter, Particle Mass Concentrations, Health Effects.

\section{INTRODUCTION}

Particulate matter (PM) pollution is of great concern due to its association with adverse effects upon human health (e.g., Pope 2000; Dockery 2001). These effects are more pronounced in densely populated cities where PM concentrations are high as a result of intensive human activity (e.g., Harrison et al., 2001; Querol et al., 2008). Indeed, as health impact assessment studies show, a reduction of the ambient concentration of $\mathrm{PM}_{10}$ by $5 \mathrm{\mu g} \mathrm{m}^{-3}$ in European cities can prevent between 3 to 8 thousand early deaths annually (Medina et al., 2004). A growing number of such studies underline the importance for systematic monitoring of PM concentration levels for facilitating control of particle-pollution sources.

Apart from local sources, PM concentrations in the atmosphere over urban and suburban areas can be affected by regional and long-range transport of natural and human-made particles. In Greece for instance, the dominance of northern winds during the summer transport polluted air masses from continental Europe to the East Mediterranean (e.g., Lelieveld et al., 2002), thereby having a significant contribution of PM concentrations in the region (Bougiatioti et al., 2009). Moreover, due to the proximity to North Africa, Saharan dust is frequently observed during spring and autumn in the region (Kaskaoutis et al., 2008). These phenomena make PM pollution in the region of particular complexity, thereby posing great challenges in the design and implementation of pollution control strategies.

Several studies have reported PM concentration measurements conducted at the two major urban centres in Greece. Kambezidis et al. (1986) were among the first ones to report PM concentration measurements at the city of Athens. Almost two decades later, Chaloulakou et al. (2003) reported a 
comprehensive yearlong (1999-2000) record of simultaneous $\mathrm{PM}_{10}$ and $\mathrm{PM}_{2.5}$ measurements conducted at a single station in the centre of Athens. In an attempt to identify the spatial variation of PM pollution in the city of Athens, Mantis et al. (2005) have reported $\mathrm{PM}_{10}$ concentration performed at four monitoring stations from 2001 to 2002. Most recently, Vardoulakis and Kassomenos (2008) and Grivas et al. (2008) have correlated three-year- (2001-2003) and four-year-long (2001-2004) PM concentration measurements, respectively, with gaseous species concentration measurements to identify the sources and to assess the temporal variation of PM pollution in the city of Athens.

PM pollution at the city of Thessaloniki has been the subject of many studies since the early 90's (e.g., Samara et al., 1990, Tsitouridou and Samara, 1993). In a more recent study, Manoli et al. (2002) have reported a yearlong record (1994-1995) of PM concentration and composition measurements from a single traffic-impacted urban site in an attempt to identify the main sources of particulate pollution in the city. To investigate the spatial and temporal variation of PM pollution, Voutsa et al. (2002) have reported similar measurements conducted at three urban sites in Thessaloniki for the period 1997-1998. Samara and Voutsa (2005), and more recently Chrysikou and Samara (2009), have provided size-segregated PM concentration and composition measurements in order to identify the potential risks associated to the inhalable fractions.

The objective of this paper is to provide an overview of the temporal variation of $\mathrm{PM}_{10}$ concentration levels in the two major urban centres in Greece over the period 2001 to 2010 . Using daily average $\mathrm{PM}_{10}$ concentration measurements provided by the standardized air pollution monitoring networks, we estimate the annual and the seasonal variation of PM concentrations for that period. Employing one-way ANOVA and Tukey's multiple comparison tests, or Welch ANOVA and Games-Howell tests depending on the homogeneity and the normality of the data, we estimate the statistically significant differences among the annual and monthly average $\mathrm{PM}_{10}$ concentrations. This analysis allows us to draw conclusions on the trends of PM pollution in the two cities and to assess the significance of human contribution.

\section{METHODS AND TECHNIQUES}

\subsection{Study areas and sampling stations}

Athens is the largest urban centre in Greece having a population of 3.8 million inhabitants (Hellenic Statistical Authority, 2011). The city is surrounded by Parnitha mountain (1413 m asl) in the North, by Penteli mountain $(1109 \mathrm{~m}$ asl) in the North-East, by Hymettus mountain $(1026 \mathrm{~m}$ asl) in the East, and by open sea (the Saronic Gulf) in the South-West. Systematic $\mathrm{PM}_{10}$ measurements in Athens are performed since 2001 by an authority of the Ministry of Environmental Physical Planning and Public Works. The measurements used in our study were collected from 2001 to 2010 from six stations in Athens, including the urban stations at Aristotelous (ARI), Maroussi (MAR), and Piraeus (PIR), and the suburban stations at Agia Paraskevi (AGP), Thrakomacedones (THR) and Lykovrissi (LYK) (cf. Figure 1).

Thessaloniki is the second largest city in Greece having a population of 1.1 million inhabitants (Hellenic Statistical Authority, 2011). The city is situated in the northern part of Greece and is surrounded in the North-Northeast by Hortiatis Mountain $(1200 \mathrm{~m}$ asl) and in the South by Thermaikos Gulf. Daily $\mathrm{PM}_{10}$ concentration measurements in Thessaloniki are conducted by the Department of Environment and Public Works of the District of Central Macedonia since 2001. The measurements used in our study have been collected during the period 2001-2010 from five stations in the city, including the urban stations at Kordelio (KOD) and Agia Sofia square (AGS), and the suburban stations at Kalamaria (KAL), Panorama (PAO), and Sindos (SIN), as shown in Figure 1. More details about the stations are available in the HMEECC (2010) report for Athens and in the RCM (2007) report for Thessaloniki. The instruments used for measuring $\mathrm{PM}_{10}$ mass concentrations at all stations in both cities are beta radiation attenuation monitors (ESM-Andersen, Model FH 62 I$\mathrm{R})$. 


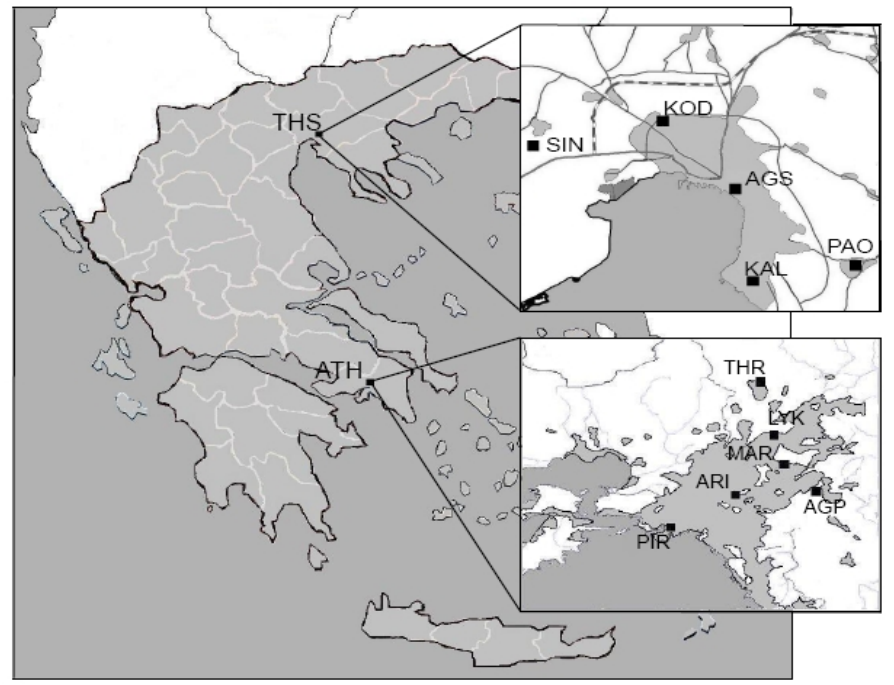

Figure 1. Map of Greece showing the cities of Athens (ATH) and Thessaloniki (THS) and the locations of the stations from which we obtained daily average $\mathrm{PM}_{10}$ concentrations

\subsection{Data Analysis}

The daily average $\mathrm{PM}_{10}$ concentration measurements from each monitoring station were grouped on an annual basis, and for each year the data were further separated in sub-groups on a monthly basis. To identify whether normal or log-normal probability density functions best fit the measurements for each group we used one-sample Kolmogorov-Smirnov (K-S) tests at a 0.05 significance level before continuing with the rest of the analysis. Normal probability density functions can be indicative of natural sources, whereas the lognormal of human sources (Zikovsky et al., 1987).

Analysis of the annual and seasonal variation for each station was conducted by one-way analysis of variance (ANOVA) to identify whether the average values for each group are significantly different among each other. The homogeneity of variance between the different groups was also investigated using Levene's test ( $p$-value of 0.05). For the groups that failed the Levene tests (i.e., the grouped measurements that did not show similar variances) we performed Welch ANOVA to identify potential differences among the average values for each sub-group. In both cases, the analysis was completed with post hoc tests to determine similarities and differences among the various groups. Depending on whether the variances among the groups were equal or not we employed Tukey Honestly Significant Difference (HSD) or the Games-Howell tests, respectively (cf. Lomax, 2007).

\section{RESULTS AND DISCUSSION}

\subsection{Annual variation}

Figure 2 shows the temporal variation of the annual average $\mathrm{PM}_{10}$ concentrations for all the monitoring stations in Athens. The stations that exhibit the highest and the lowest concentrations during the entire period we investigated are LYK and THR having average values 54.6 and $30.3 \mu \mathrm{g}$ $\mathrm{m}^{-3}$, respectively. Interestingly, both the highest and the lowest concentrations are observed at suburban stations. The high values at LYK can be explained by the fact that the station is located in an area that is characterized by high agricultural activity and is also close (at a distance of ca. $100 \mathrm{~m}$ ) to a highway. For the urban stations, the highest and the lowest values are observed at ARI and MAR with average values 54.0 and $47.2 \mu \mathrm{g} \mathrm{m}^{-3}$, respectively. The EU annual $\mathrm{PM}_{10}$ concentration limit of $40 \mathrm{\mu g} \mathrm{m}^{-3}$ (European Council Directive 1999/30/EC) was exceeded at all urban stations and at the suburban station of LYK for almost the entire period that we investigated. The EU 24-h PM10 limit (i.e., concentrations higher than $50 \mu \mathrm{g} \mathrm{m}^{-3}$ for more than 35 days per year) was exceeded for all the urban stations in Athens during the period we investigated. For the suburban stations, LYK exceeded the EU 24-h $\mathrm{PM}_{10}$ limit for the entire period from 2001 to 2010 , whereas THR only for 2010 and AGP only from 2001 to 2005.

In general, the annual average $\mathrm{PM}_{10}$ concentrations in Athens are higher at the urban than at the suburban stations. The average $\mathrm{PM}_{10}$ concentration at the urban stations ( $P I R, A R I$ and MAR) is $50.1 \mathrm{\mu g} \mathrm{m}^{-3}$, while the respective value for the suburban stations (LYK, THR and AGP) is $39.8 \mu \mathrm{g} \mathrm{m}^{-3}$ for the entire period that we investigated (2001 to 2010). Excluding the measurements at LYK, which 
are affected by high traffic and agricultural activity as mentioned above, the average $\mathrm{PM}_{10}$ concentrations for the suburban stations in Athens is $32.5 \mu \mathrm{g} \mathrm{m}^{-3}$. An overall decrease in $\mathrm{PM}_{10}$ concentrations is observed at PIR (by $29.2 \mu \mathrm{g} \mathrm{m}^{-3}$ ), in MAR (by $14.9 \mu \mathrm{g} \mathrm{m}^{-3}$ ), in AGP (by $18.3 \mu \mathrm{g} \mathrm{m}^{-3}$ ) and in LYK (by $21.1 \mathrm{\mu g} \mathrm{m}^{-3}$ ) during the entire period. ARI shows fairly constant concentration levels with values ranging from 51.7 to $57.9 \mu \mathrm{g} \mathrm{m}^{-3}$ throughout the period from 2001 to 2008 , and a decrease (by $7.9 \mathrm{\mu g} \mathrm{m}^{-3}$ ) from 2008 to 2010 . The only station that shows an increase of the annual average concentration are THR (by $15.2 \mu \mathrm{g} \mathrm{m}^{-3}$ ) from 2008 to 2010.

$\mathrm{K}-\mathrm{S}$ tests revealed that the probability density functions of the measurements for each year and each station can be represented in almost all the cases by lognormal distributions. Investigation of the homogeneity of annual variances (Levene's test) shows that there are no significant deviations among the annual average $\mathrm{PM}_{10}$ concentrations in ARI, LYK and THR (p-value of 0.05). Using oneway ANOVA for those stations, the $\mathrm{PM}_{10}$ annual average concentrations were found to vary significantly ( $p$-value of 0.05 ) from one another. Tukey HSD tests showed that four groups of $\mathrm{PM}_{10}$ annual average concentrations having values of $27.9 \mu \mathrm{g} \mathrm{m}^{-3}$ for the years $2001-2005$ and 2009 (pvalue of 0.444 ), $23.1 \mu \mathrm{g} \mathrm{m}^{-3}$ for the years 2006 and 2008 ( $\mathrm{p}$-value of 1.000 ), $31.1 \mathrm{\mu g} \mathrm{m}^{-3}$ for the years 2002 and 2010 ( $p$-value of 0.056 ), and $18.8 \mu \mathrm{g} \mathrm{m}^{-3}$ for the year 2007 ( $p$-value of 1.000) can be identified for THR. This grouping indicates that the variability in the annual $\mathrm{PM}_{10}$ concentration for this station is random. In a similar manner, three groups can be distringuished for LYK, having $\mathrm{PM}_{10}$ annual average values of $55.6 \mu \mathrm{g} \mathrm{m}^{-3}$ for the years 2001-2004 (p-value 0.152 ), $50.3 \mathrm{\mu g} \mathrm{m}^{-3}$ for the years 2005-2008 ( $p$-value 0.142 ) and $36.1 \mu^{-3} \mathrm{~m}^{-3}$ for the years 2009-2010 ( $p$-value 0.116 ), showing a clear decreasing trend. Two main groups can be distringuished for ARI having mean values of 51.3 $\mu \mathrm{g} \mathrm{m}^{-3}$ for the years 2001 to 2008 ( $\mathrm{p}$-value of 0.106 ) and $44.7 \mu \mathrm{g} \mathrm{m}^{-3}$ for the years 2009 and 2010 ( $\mathrm{p}$ value 0.142 ).

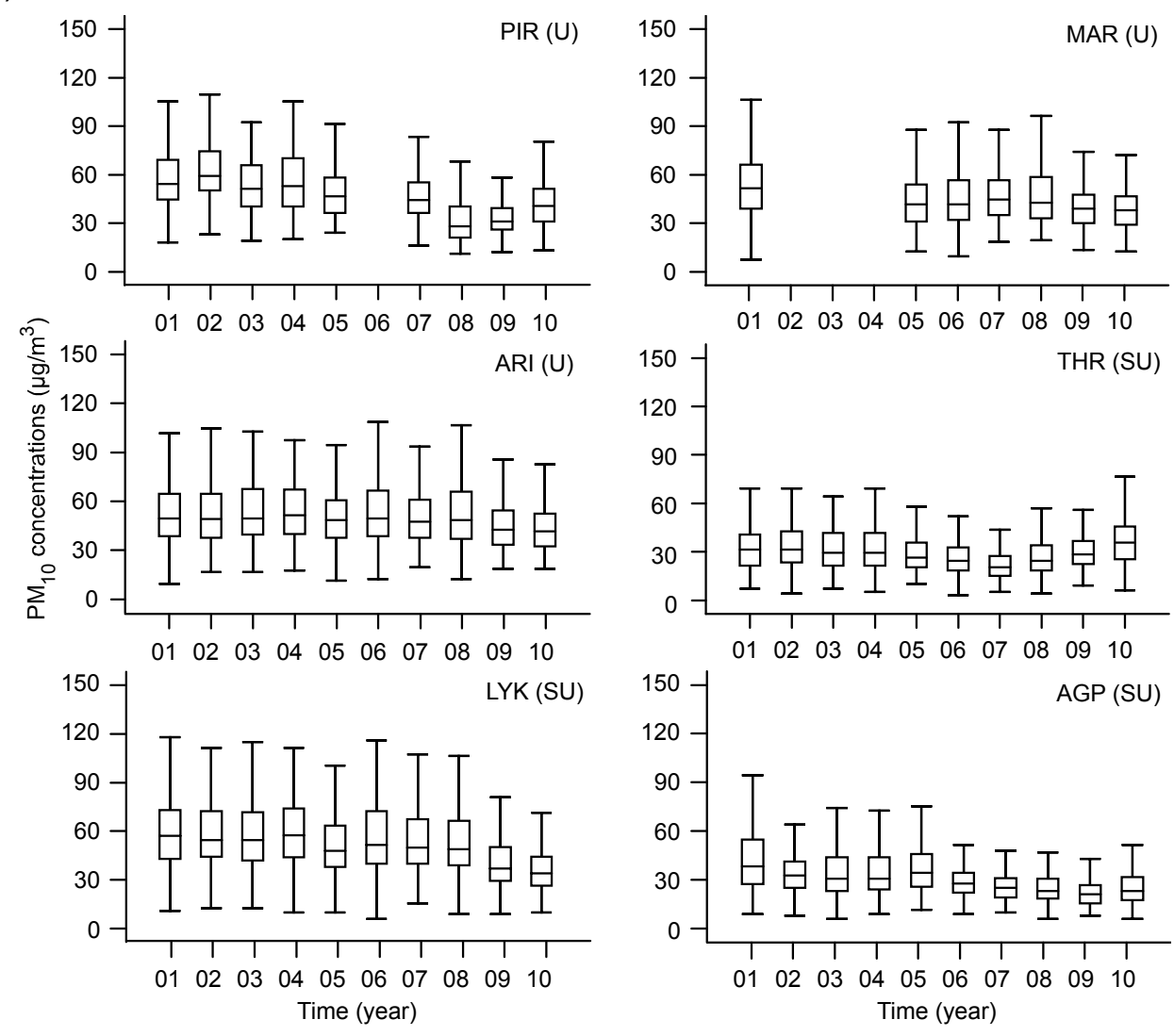

Figure 2. Annual average $\mathrm{PM}_{10}$ concentrations $\left(\mu \mathrm{g} \mathrm{m}^{-3}\right)$ at three urban (PIR, MAR, ARI) and three suburban (LYK, THR, AGP) monitoring stations in Athens. Each box plot shows the median (middle line of the box), upper (25\%) and lower (75\%) quartile (top and bottom lines of the box, respectively) as well as the minimum and maximum values (upper and lower end of the whisker lines)

For the stations PIR, MAR and AGP that exhibit data inhomogeneity we used the Welch ANOVA and the Games-Howell post hoc test. In all these stations, the Welch ANOVA showed significant differences among the $\mathrm{PM}_{10}$ annual average concentrations from one year to another ( $p$-value of 
0.05). The Games-Howell post hoc tests showed that three groups can be distringushed for PIR. The first includes the years 2001-2005 having an annual average $P_{10}$ concentration of $53.1 \mathrm{\mu g} \mathrm{m}^{-3}(\mathrm{p}-$ value of 0.599 ), the second includes the years 2005, 2007 and 2010 and has an average value of $44.2 \mu \mathrm{g} \mathrm{m}^{-3}$ ( $\mathrm{p}$-value 0.351 ), and the third the years 2008 and 2009 with an average value of $29.6 \mu \mathrm{g}$ $\mathrm{m}^{-3}$ ( $\mathrm{p}$-value 0.357 ). This classification indicates that although a statistically significant decrease is observed at PIR after 2005, the variation in $\mathrm{PM}_{10}$ concentrations from 2007 to 2010 is random. In a similar manner, two groups can be distringushed for MAR: one including the years 2005-2008 having an average value of $43.6 \mu \mathrm{g} \mathrm{m}^{-3}$ (p-value of 0.991), and one including the years 2009 and 2010 with an average value of $38.4 \mu \mathrm{g} \mathrm{m}^{-3}$ ( $\mathrm{p}$-value of 0.774 ), indicating that there is a systematic decreasing trend. Finally, the annual average concentrations observed in AGP can be divided in four groups that are significantly different from one another: the first group includes the years 2002-2004 and has an annual average $\mathrm{PM}_{10}$ concentration of $33.7 \mu \mathrm{g} \mathrm{m}^{-3}$ ( $\mathrm{p}$-value of 0.939 ), the second group includes the years 2002, 2004 and 2005 and has an average value of $35.0 \mathrm{\mu g} \mathrm{m}^{-3}$ ( $p$-value of 0.517 ), the third includes the years 2003 and 2006 and has an average value of $31.3 \mu \mathrm{g} \mathrm{m}^{-3}$ ( $p$-value of 0.462 ), and the forth group includes the years 2007, 2008 and 2010 having an average value of $25.4 \mathrm{\mu g} \mathrm{m}^{-3}(\mathrm{p}-$ value of 0.990 ). This classification suggests that there is a statistically significant decreasing trend of $\mathrm{PM}_{10}$ concentrations at $\mathrm{AGP}$ over the years that are investigated in this paper.

Figure 3 shows the temporal variation of the annual average $\mathrm{PM}_{10}$ concentrations for all monitoring stations in Thessaloniki. The stations that exhibit the highest and the lowest values are the urban station KOD (having an average value of $59.2 \mu \mathrm{g} \mathrm{m}^{-3}$ ) and the suburban station PAO (having an average value of $30.3 \mu \mathrm{g} \mathrm{m}^{-3}$ ), respectively. The annual average $\mathrm{PM}_{10}$ concentrations at the two urban stations KOD and AGS, as well as the suburban station SIN are considerably higher than the annual EU limit value. The $\mathrm{PM}_{10}$ concentrations at the suburban station KAL also exceed the annual limit for the year 2008, while the measurements at PAO are below the limit for the entire ten-year period that we investigated. The 24-h limit is exceeded in both the urban and the suburban stations in Thessaloniki during the entire period we investigated. The only exceptions are the urban station AGS in 2004 (only 28 days exhibited 24-h $\mathrm{PM}_{10}$ concentrations higher than $50 \mu \mathrm{g} \mathrm{m}^{-3}$ ), the suburban station of SIN in 2009 (21 days having $\mathrm{PM}_{10}$ concentrations higher than $50 \mathrm{\mu g} \mathrm{m}^{-3}$ ) and the suburban station PAO for the periods 2003-2004, and 2006-2009 (26 and 12 days exhibit concentrations higher than $50 \mathrm{\mu g} \mathrm{m}^{-3}$, respectively). The station with the most days above the 24-h limit was AGS (with 149 days per year in average), which is located in the center of the city.

In general, the annual average $\mathrm{PM}_{10}$ concentrations in Thessaloniki are higher at the urban stations than at the suburban stations. The average $\mathrm{PM}_{10}$ concentrations at the urban stations (KOD and AGS) are $57.7 \mathrm{\mu g} \mathrm{m}^{-3}$, whereas for the suburban stations (SIN, KAL, and PAO) the respective value is $37.7 \mu \mathrm{g} \mathrm{m}^{-3}$ for the period 2001-2010. Interestingly, the $\mathrm{PM}_{10}$ concentrations at the urban stations of Thessaloniki are much higher compared to those at the urban stations in Athens. An explanation that has been offered for this observation is that apart from heavy traffic there is intensive industrial activity in the city of Thessaloniki (Samara et al., 2003; Moussiopoulos et al., 2009). It is worth noting that $20 \%$ of the industrial activity of the country is located in this area.

Despite the high values, an overall decrease of the $\mathrm{PM}_{10}$ annual average concentrations is observed at almost all the monitoring stations in Thessaloniki from 2001 to 2010 . More specifically, a decrease is observed for the urban stations of KOD (by $27.3 \mu \mathrm{g} \mathrm{m}^{-3}$ ) and of AGS (by $17.3 \mu \mathrm{g} \mathrm{m}^{-3}$ ), as well as for the suburban stations of PAO (by $13.5 \mu \mathrm{g} \mathrm{m}^{-3}$ ) for the entire period we inverstigated, of SIN (by $6.3 \mu \mathrm{g} \mathrm{m}^{-3}$ ) from 2008-2009, and of KAL (by $20 \mu \mathrm{g} \mathrm{m}^{-3}$ ) from 2007 to 2010 (measurements are not available for previous years for this station). SIN is the only station that does not show any increasing or decreasing trend, having $\mathrm{PM}_{10}$ concentrations that vary randomly between 44.9 and $51.5 \mathrm{\mu g} \mathrm{m}^{-3}$ from 2001 to 2008 . This observation can be explained by the fact that the station is located close to the industrial zone of the city, which is a continuous and constant source of PM pollution.

The K-S tests revealed that the measurements for each year at each station can be well represented in almost all the cases by lognormal distributions. The only exceptions are the measurements from PAO during 2007 and SIN during 2009, which follow a normal distribution. The Levene's test showed that the variances do not differ significantly among the different years in SIN and PAO ( $p$-value of 0.05), indicating that either the sources or the conditions affecting the $\mathrm{PM}_{10}$ concentrations are similar for all the years. One-way ANOVA for these two stations showed that the $\mathrm{PM}_{10}$ annual average concentrations vary significantly from one another ( $p$-value of 0.05 ). The Tukey HSD tests 
showed that annual average $\mathrm{PM}_{10}$ concentrations at SIN can be classified in three groups having significantly different values: the first with an average value of $45.5 \mu \mathrm{g} \mathrm{m}^{-3}$ for the years $2001-2003$, and 2006-2008 ( $p$-value of 0.443), the second $38.7 \mu \mathrm{g} \mathrm{m}^{-3}$ for 2004 and 2009 ( $\mathrm{p}$-value of 0.726 ), and the third group $42.7 \mathrm{\mu g} \mathrm{m}^{-3}$ for 2002, 2004 and 2008 ( $\mathrm{p}$-value of 0.063 ). The annual average $\mathrm{PM}_{10}$ values at PAO can be classified in three groups: the first one having average value of $32.4 \mu \mathrm{g} \mathrm{m}^{-3}$ for the years 2001 and 2002 ( $p$-value of 0.143 ), the second $29.4 \mu \mathrm{g} \mathrm{m}^{-3}$ for the years 2002-2004 and 2006 ( $p$-value of 0.076 ), and the third $22.7 \mu \mathrm{g} \mathrm{m}^{-3}$ for 2007 and 2009 ( $p$-value of 0.252 ). Despite the lack of data for the years 2008 and 2010, an overall decreasing trend is observed at this station.

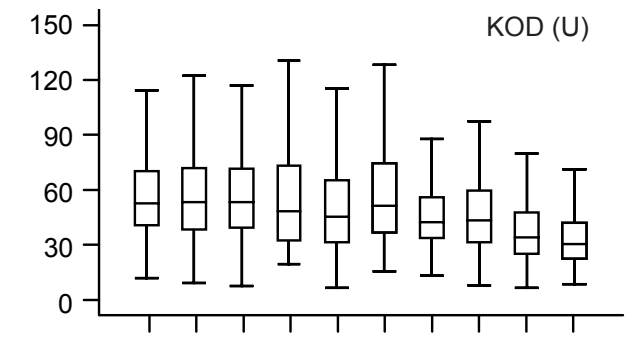

$\begin{array}{llllllllll}01 & 02 & 03 & 04 & 05 & 06 & 07 & 08 & 09 & 10\end{array}$
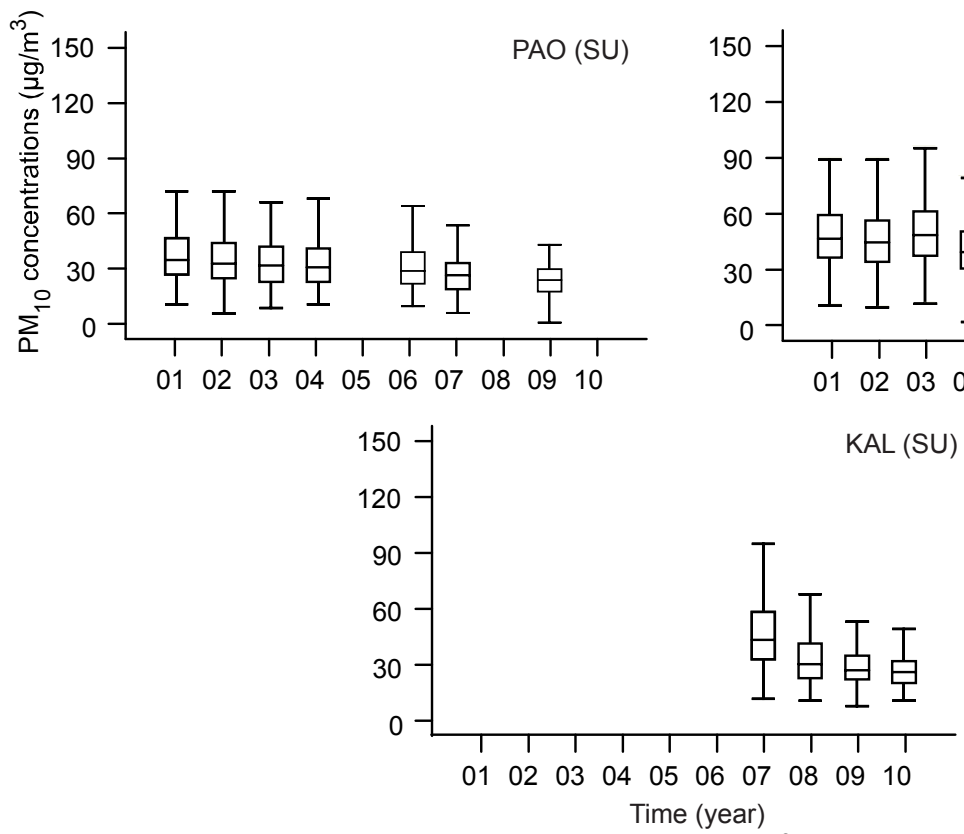

$\operatorname{AGS}(U)$

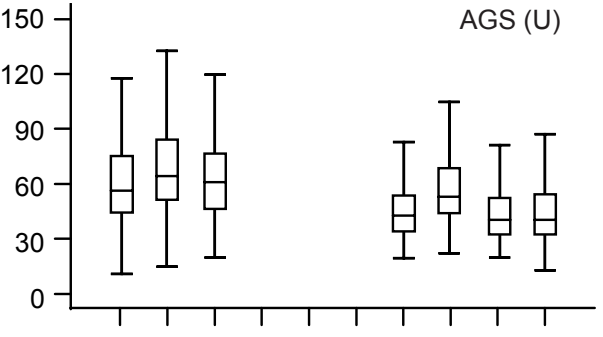

$\begin{array}{llllllllll}01 & 02 & 03 & 04 & 05 & 06 & 07 & 08 & 09 & 10\end{array}$

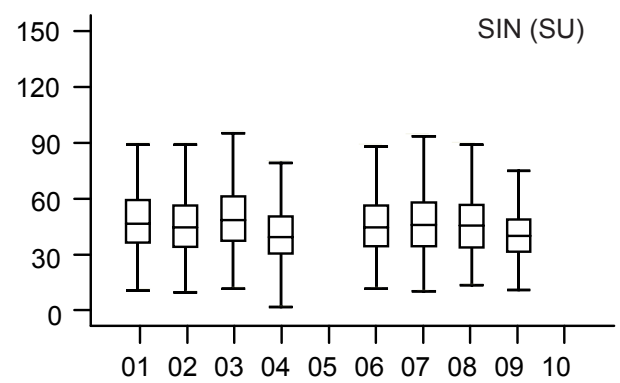

KAL (SU)

.

Figure 3. Annual average $\mathrm{PM}_{10}$ concentrations $\left(\mu \mathrm{g} \mathrm{m}^{-3}\right)$ at two urban (KOD, AGS) and three suburban (PAO, SIN, KAL) monitoring stations in Thessaloniki. Each box plot shows the median (middle line of the box), upper (25\%) and lower (75\%) quartile (top and bottom lines of the box, respectively) as well as the minimum and maximum values (upper and lower end of the whisker lines)

Because of the significantly different variances for the annual average $\mathrm{PM}_{10}$ measurements at the stations KOD, AGS, and KAL (as indicated by the Levene's tests), we proceed with the Welch ANOVA and Games-Howell post hoc tests. The analysis showed that the annual average $\mathrm{PM}_{10}$ concentrations vary significantly from one another ( $p$-value of 0.05 ) at all these stations. The GamesHowell post hoc tests revealed that three groups of $\mathrm{PM}_{10}$ annual average concentrations can be distinguished for KOD: the first one having mean value of $59.1 \mu^{-3} \mathrm{~m}^{-3}$ for the years 2001-2006 (pvalue of 0.926 ), the second $51.0 \mu \mathrm{g} \mathrm{m}^{-3}$ for the years 2005,2007 , and 2008 ( $p$-value 0.938 ), and the third $38.3 \mu \mathrm{g} \mathrm{m}^{-3}$ for the years 2009-2010 ( $p$-value of 0.830 ). This classification indicates a clear decreasing trend over the years that were investigated. At AGS the annual average $P_{10}$ concentrations can be categorized in two groups that differ significantly from one another: the first includes the years 2001, 2003 and 2008 and has a mean value of $56.4 \mathrm{\mu g} \mathrm{m}^{-3}$ ( $p$-value of 0.700 ), whereas the second includes the years 2007, 2009 and 2010 and has a mean value of $45.7 \mu \mathrm{g} \mathrm{m}^{-3}$ ( $p$-value of 0.790$)$. Finally, at KAL the annual average concentrations are significantly different among each other for the entire period that data were available (i.e., from 2007 to 2010), showing a 
systematic decreasing trend over the years.

\subsection{Seasonal and monthly variation}

As shown in Figure 4, the highest monthly average $\mathrm{PM}_{10}$ values at the urban stations in Athens are observed during the autumn/winter seasons and the lowest during the summer. For the suburban stations the respective values are observed during the spring and during the winter. This systematic difference between the urban and the suburban stations in Athens indicates that the former are influenced to a greater extent by sources that exhibit seasonality (e.g., domestic heating systems) compared to other PM sources (e.g., traffic).

The urban stations MAR and ARI exhibit higher monthly-average concentrations in November (56.2 and $65.8 \mu \mathrm{g} \mathrm{m}^{-3}$, respectively) and lower in June $\left(39.7 \mu \mathrm{g} \mathrm{m}^{-3}\right)$ and August $\left(47.5 \mu \mathrm{g} \mathrm{m}^{-3}\right)$, respectively. The $\mathrm{PM}_{10}$ concentrations measured at the urban station PIR ranged between 40.6 and $53.7 \mathrm{\mu g} \mathrm{m}^{-3}$ without showing any significant monthly variations. This can be explained by the fact that the station of PIR is located close to the main port of Athens, and as a result is influenced by its intensive activity. Monthly average $\mathrm{PM}_{10}$ concentrations measured at the suburban stations of THR and AGP (cf. Figure 4) were found to be higher in April and in September (having average values of 41.3 and $40.0 \mu \mathrm{g} \mathrm{m}^{-3}$, respectively) and lower in December (having average values of 22.5 and 24.3 $\mu \mathrm{g} \mathrm{m}^{-3}$, respectively). At AGP and THR, the measurements showed systematically higher concentrations during April for all the years. This observation suggests that both these stations, which are situated close to pine and conifer forests, are significantly influenced by the spring flowering period (Apostolou \& Yannitsaros, 1977; Vassilakos et al., 2005). Measurements at the other suburban station (i.e., LYK) showed higher $\mathrm{PM}_{10}$ concentrations in November and lower in August $\left(60.7\right.$ and $49.5 \mathrm{\mu g} \mathrm{m}^{-3}$, respectively). This observation suggests that $\mathrm{PM}_{10}$ concentrations at LYK are predominantly determined by sources (e.g., the high traffic on the highway located $<100 \mathrm{~m}$ away) other than flowering.

The variance of the monthly average $\mathrm{PM}_{10}$ measurements at all stations was found to be inhomogeneous as indicated by the Levene's tests ( $p$-value of 0.05 ). With the exception of PIR, Welch ANOVA and Games-Howell post hoc tests showed that the seasonal average concentrations were significantly different from one another ( $p$-value of 0.05 ) for all the stations in Athens. The Games-Howell test at PIR showed that although the average $\mathrm{PM}_{10}$ concentrations in spring (44.6 $\mu \mathrm{g}$ $\left.\mathrm{m}^{-3}\right)$ and winter $\left(42.9 \mathrm{\mu g} \mathrm{m}^{-3}\right)$ are higher compared to those in autumn $\left(42.4 \mathrm{\mu g} \mathrm{m}^{-3}\right)$ and summer $\left(41.0 \mu \mathrm{g} \mathrm{m}^{-3}\right)$, they do not differ significantly from each other $(\mathrm{p}$-value of 0.508$)$. At MAR the respective concentrations for winter $\left(45.3 \mathrm{\mu g} \mathrm{m}^{-3}\right)$ and autumn $\left(43.4 \mathrm{\mu g} \mathrm{m}^{-3}\right)$ do not differ significantly from each other ( $p$-value of 0.478 ), but are significantly higher compared to those in spring (43.1 $\mu \mathrm{g}$ $\mathrm{m}^{-3}$ ) and summer $\left(40.6 \mu \mathrm{g} \mathrm{m}^{-3}\right)$. In a similar manner, the $\mathrm{PM}_{10}$ concentrations in spring $\left(29.4 \mu \mathrm{g} \mathrm{m}^{-3}\right)$ and summer $\left(29.1 \mathrm{\mu g} \mathrm{m}^{-3}\right)$ are similar ( $\mathrm{p}$-value of 0.947$)$ at THR, and significantly higher compared to autumn $\left(24.9 \mathrm{\mu g} \mathrm{m}^{-3}\right)$ and winter $\left(19.5 \mu \mathrm{g} \mathrm{m}^{-3}\right)$. At ARI the average $\mathrm{PM}_{10}$ values in autumn, winter and spring do not differ significantly ( $p$-value of 0.355 ) from each other (having average values 52.7 $\mu \mathrm{g} \mathrm{m}^{-3}, 49.9 \mathrm{\mu g} \mathrm{m}^{-3}$ and $49.4 \mathrm{\mu g} \mathrm{m}^{-3}$, respectively), but are significantly higher compared to those in summer $\left(46.7 \mathrm{\mu g} \mathrm{m}^{-3}\right)$. At LYK the $\mathrm{PM}_{10}$ concentrations for spring, summer and autumn, do not vary significantly ( $p$-value of 0.543 ) from each other (having average values $50.9,48.9$ and $48.0 \mu \mathrm{g} \mathrm{m}^{-3}$ ), but are significantly higher compared to the measured values in winter $\left(46.8 \mu \mathrm{g} \mathrm{m}^{-3}\right)$. Finally, at AGP the respective $\mathrm{PM}_{10}$ values for summer and spring do not differ significantly ( $p$-value of 0.059 ) from each other (having average values $34.9 \mathrm{\mu g} \mathrm{m}^{-3}$ and $32.9 \mathrm{\mu g} \mathrm{m}^{-3}$ ), but are much higher compared to those in autumn $\left(30.4 \mathrm{\mu g} \mathrm{m}^{-3}\right)$ and in winter $\left(23.2 \mathrm{\mu g} \mathrm{m}^{-3}\right)$. 

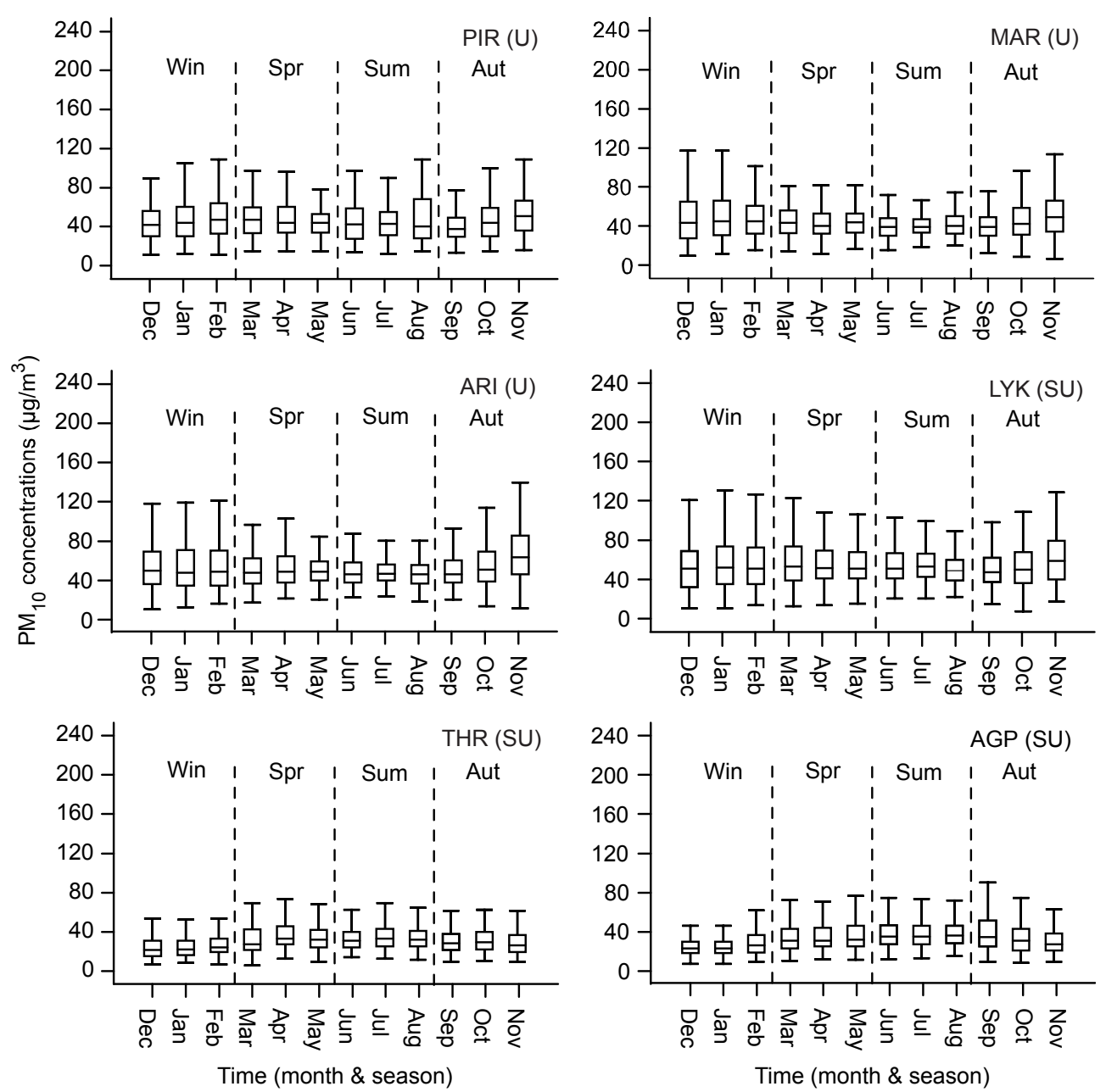

Figure 4. Monthly average $\mathrm{PM}_{10}$ concentrations $\left(\mu \mathrm{g} \mathrm{m}^{-3}\right)$ at three urban (PIR, MAR, ARI) and three suburban (LYK, THR, AGP) monitoring stations in Athens. Each box plot shows the median (middle line of the box), upper $25 \%$ and lower $75 \%$ quartile (top and bottom lines of the box, respectively) and the minimum and maximum values (upper and lower end of the whisker lines)

Both urban and suburban stations in Thessaloniki exhibit the highest monthly average $\mathrm{PM}_{10}$ values during the "cold" seasons (autumn and winter) and the lowest during the summer. The only exception is PAO station that exhibits highest seasonal average $\mathrm{PM}_{10}$ values during spring and the lowest during the winter. This seasonal difference could be attributed to the fact that the station is located close to a forest, which can be an important source of airborne particles (e.g., pollen) during the flowering period (April to July). As shown in Figure 5, the stations KOD, AGS, and SIN exhibit the highest $\mathrm{PM}_{10}$ concentrations in November (with average values 78.4, 75.9 and $64.1 \mu \mathrm{g} \mathrm{m}^{-3}$, respectively) and the lowest in July $\left(50.1 \mathrm{\mu g} \mathrm{m}^{-3}\right)$, July $\left(48.6 \mathrm{\mu g} \mathrm{m}^{-3}\right)$ and March $\left(43.6 \mu \mathrm{g} \mathrm{m}^{-3}\right)$, respectively. The suburban stations KAL and PAO exhibit the highest monthly average $\mathrm{PM}_{10}$ concentrations in November $\left(48.0 \mathrm{\mu g} \mathrm{m}^{-3}\right)$ and in April $\left(34.4 \mathrm{\mu g} \mathrm{m}^{-3}\right)$, and the lowest in September $\left(30.6 \mathrm{\mu g} \mathrm{m}^{-3}\right)$ and in December $\left(29.0 \mathrm{\mu g} \mathrm{m}^{-3}\right)$, respectively.

The seasonal variations of the log-transformed $\mathrm{PM}_{10}$ concentrations differ significantly among the different seasons in all the monitoring stations (Levene's test, p-value 0.05). The Welch ANOVA and the Games-Howell post hoc tests showed that the seasonal average $\mathrm{PM}_{10}$ concentrations also vary significantly from one another for all the monitoring stations. The seasonal average $\mathrm{PM}_{10}$ values at KOD for autumn and winter (average values of 55.2 and $56.5 \mathrm{\mu g} \mathrm{m}^{-3}$, respectively) do not differ significantly from each other ( $p$-value of 0.892$)$, but are higher compared to those in spring $\left(49.8 \mu \mathrm{g} \mathrm{m}^{-3}\right)$ and summer $\left(47.9 \mathrm{\mu g} \mathrm{m}^{-3}\right)$. In a similar manner, the respective concentrations for autumn $\left(55.9 \mathrm{\mu g} \mathrm{m}^{-3}\right)$ and winter $\left(53.5 \mathrm{\mu g} \mathrm{m}^{-3}\right)$ at AGS do not differ significantly from each other ( $p$-value of 0.429$)$, but are higher compared to those in spring and summer $\left(48.7 \mathrm{\mu g} \mathrm{m}^{-3}\right.$ and $47.4 \mathrm{\mu g} \mathrm{m}^{-3}$, respectively). The average $\mathrm{PM}_{10}$ values at PAO do not differ significantly ( $p$-value of 0.865 ) between summer and spring (having average values of $29.5 \mu \mathrm{g} \mathrm{m}^{-3}$ and $29.0 \mu \mathrm{g} \mathrm{m}^{-3}$, respectively), but are higher 
compared to winter $\left(27.0 \mu \mathrm{g} \mathrm{m}^{-3}\right)$. For SIN, the seasonal average $\mathrm{PM}_{10}$ values do not differ significantly ( $p$-value of 0.997 ) for winter and summer $\left(43.7 \mathrm{\mu g} \mathrm{m}^{-3}\right.$ and $43.9 \mu \mathrm{g} \mathrm{m}^{-3}$, respectively), but are significantly higher compared to spring $\left(40.7 \mu \mathrm{g} \mathrm{m}^{-3}\right)$. Finally the concentrations at KAL do not differ significantly ( $p$-value of 0.518 ) for winter and autumn $\left(37.0 \mu \mathrm{g} \mathrm{m}^{-3}\right.$ and $34.5 \mu \mathrm{g} \mathrm{m}^{-3}$, respectively), but are significantly higher compared to spring and summer $\left(30.5 \mu \mathrm{g} \mathrm{m}^{-3}\right.$ and $30.1 \mu \mathrm{g} \mathrm{m}^{-3}$, respectively).

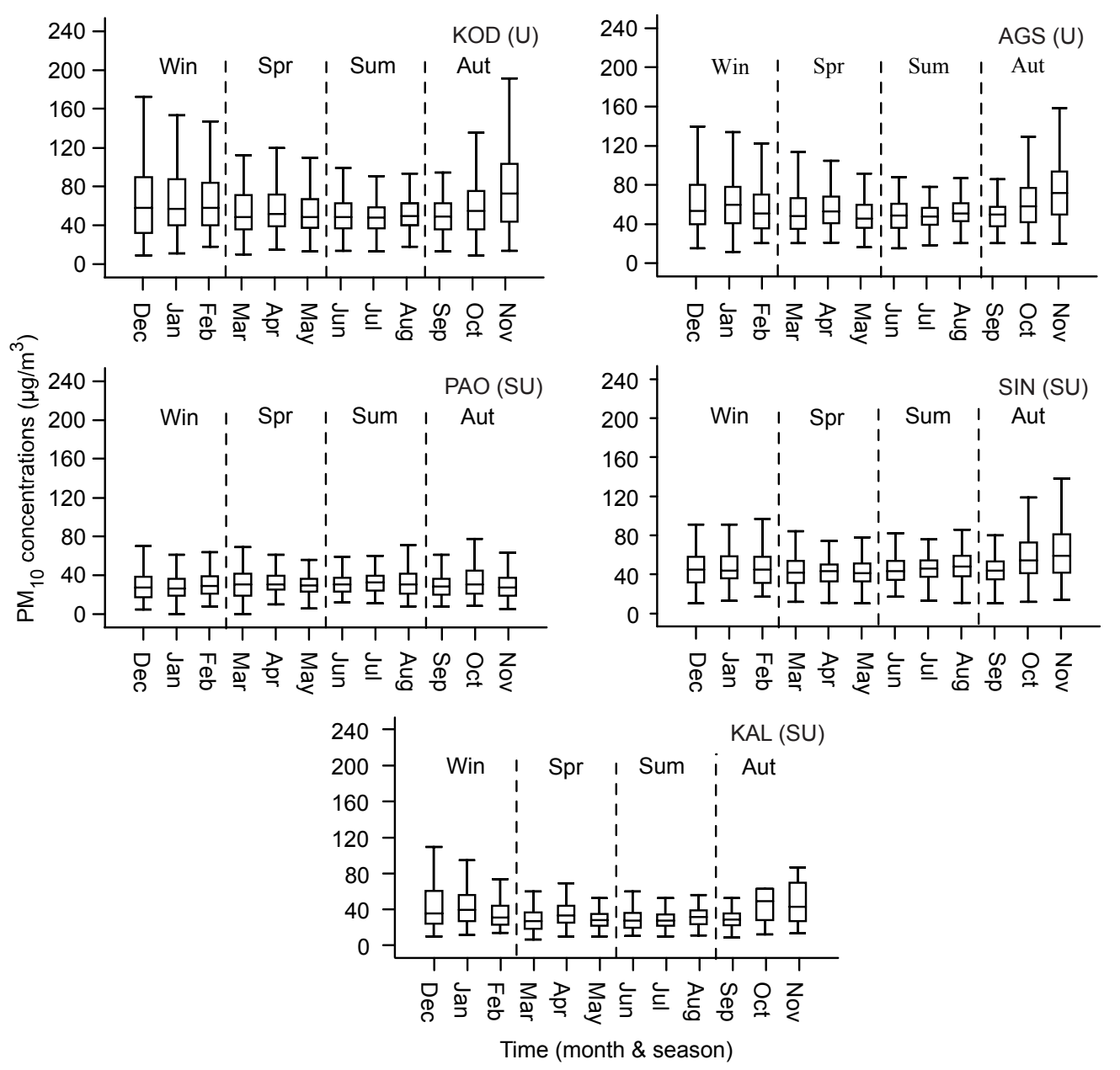

Figure 5. Monthly average $\mathrm{PM}_{10}$ concentrations $\left(\mu \mathrm{g} \mathrm{m}^{-3}\right)$ at two urban (KOD, AGS) and three suburban (PAO, SIN, KAL) monitoring stations in Thessaloniki. Each box plot shows the median (middle line of the box), upper $25 \%$ and lower $75 \%$ quartile (top and bottom lines of the box, respectively) and the minimum and maximum values (upper and lower end of the whisker lines)

\section{CONCLUSIONS}

The two major urban centres in Greece, Athens and Thessaloniki, exhibit high $\mathrm{PM}_{10}$ concentrations, compared to other European and US cities of the same size. In both cities, all urban stations exceeded the EU annual and 24-h limits during the entire period that we investigated. With the exception of LYK and AGP in Athens, and of SIN and KAL in Thessaloniki, all suburban stations showed lower than the EU limit $\mathrm{PM}_{10}$ concentration levels. The urban stations in Thessaloniki exhibited higher $\mathrm{PM}_{10}$ concentrations, compared to those in Athens, which can be attributed to the more intensive industrial activity in the city.

The annual average $\mathrm{PM}_{10}$ concentrations exhibited an overall decreasing trend in both cities during the entire period we investigated. Exceptions to this observation were observed for the suburban station of THR in Athens, that showed an increasing trend from 2007 to 2010, as well as for the stations PIR in Athens and SIN in Thessaloniki that did not exhibit any statistically significant trend, most likely due to their proximity to constant PM sources (the station at PIR is close to the main port of the country, whereas the station at SIN is close to an industrial zone). The seasonal variation was 
shown to be different between urban and suburban stations in Athens and Thessaloniki. The highest $\mathrm{PM}_{10}$ concentrations at the urban stations in Athens were higher during autumn and winter and lower during summer, while the highest values at the suburban stations were observed during the spring and the lowest during the winter. A possible explanation for this difference is that the former are influenced to a greater extent by domestic heating systems compared to other sources of $\mathrm{PM}_{10}$. In Thessaloniki, with the exception of one station (SIN) that does not exhibit any seasonality, seasonal variations were found to be similar both at the urban and the suburban stations, exhibiting highest and lowest concentrations during autumn and summer, respectively.

\section{ACKNOWLEDGEMENTS}

The authors would like to thank Dr. A. Adamopoulos and Mr. A. Vavatzanidis for providing access to the $\mathrm{PM}_{10}$ measurements. ET would also like to thank Dr. Th. Kontos for his valuable assistance and Prof. G. Matsinos for the constructive discussions, as well as the Greek State Scholarships Foundation (IKY) for funding her studies.

\section{REFERENCES}

Apostolou E.K. and Yannitsaros A.G., (1977), Atmospheric pollen in the area of Athens, Allergy, 32, 109117.

Bougiatioti A. et al., (2009), Cloud condensation nuclei measurements in the marine boundary layer of the Eastern Mediterranean: CCN closure and droplet growth kinetics, Atmospheric Chemistry and Physics, 9, 7053-7066.

Chaloulakou A. et al., (2003), Measurements of $\mathrm{PM}_{10}$ and $\mathrm{PM}_{2.5}$ particle concentrations in Athens, Greece, Atmospheric Environment, 37, 649-660.

Chrysikou L.P. and Samara C., (2009), Seasonal variation of the size distribution of urban particulate matter and associated organic pollutants in the ambient air, Atmospheric Environment, 43, 45574569.

Dockery D.W., (2001), Epidemiologic Evidence of Cardiovascular Effects of Particulate Air Pollution, Environmental Health Perspectives, 109, 483-486.

European Council Directive 1999/30/EC, Relating to limit values for sulphur dioxide, nitrogen dioxide and oxides of nitrogen, particulate matter and lead in ambient air. Official Journal of the European Communities, L163, 41-60.

Hellenic Statistical Authority, (2011), Press Release: Temporarily results of population census in Greece through 10 to 24 May 2011. Available at http://www.statistics.gr.

Grivas G., Chaloulakou A. and Kassomenos P., (2008), An overview of the $\mathrm{PM}_{10}$ pollution problem, in the Metropolitan Area of Athens, Greece, Assessment of controlling factors and potential impact of long range transport, Science of the Total Environment, 389, 165-177.

Harrison R. et al., (2001), Studies of the coarse particle $(2.5-10 \mu \mathrm{m})$ component in UK urban atmospheres, Atmospheric Environment, 35, 3667-3679.

Kambezidis H., Kassomenos P. and Kiriaki E., (1986), Smoke concentration levels in a monitoring network in Athens, Greece, Atmospheric Environment, 20, 601-604.

Kaskaoutis, D.G. et al., (2008), Study on an intense dust storm over Greece, Atmospheric Environment, 42, $6884-6896$.

Lelieveld J., Berresheim H. and Borrmann S., (2002), Global air pollution crossroads over the Mediterranean, Science, 298, 794-799.

Lomax R.G., (2007), An introduction to statistical concepts, Second Edition Lawrence Erlbaum Associates.

Manoli E., Voutsa D. and Samara C., (2002), Chemical characterization and source identification/apportionment of fine and coarse air particles in Thessaloniki, Greece, Atmospheric Environment, 36, 949-961.

Mantis J., Chaloulakou A. and Samara C., (2005), PM 10 -bound polycyclic aromatic hydrocarbons (PAHs) in the Greater Area of Athens, Greece, Chemosphere, 59, 593-604.

Medina S., Plasencia A., Ballester F., Mucke H.G. and Schwartz J. (2004), Apheis: public health impact of $\mathrm{PM}_{10}$ in 19 European cities, Journal of Epidemiology \& Community Health, 58, 831-836.

HMEECC (Hellenic Ministry of Environment Energy \& Climate Change), Directorate of air quality, (2010), Atmospheric pollution in Athens - 2009 (in Greek). Available at http://www.ypeka.gr/Default.aspx?tabid=490\&language=el-GR. 
Moussiopoulos N. et al., (2009), Air quality status in Greater Thessaloniki Area and the emission reductions needed for attaining the EU air quality legislation, Science of the Total Environment, 407, 1268-1285.

Pope III, C.A. (2000), Epidemiology of Fine Particulate Air Pollution and Human Health: Biologic Mechanisms and Who's at Risk?, Environmental Health Perspectives, 108, 713-723.

Querol X. et al., (2008), PM speciation and sources in Mexico during the MILAGRO-2006 Campaign, Atmospheric Chemistry and Physics, 8, 111-128.

RCM (Region of Central Macedonia), Directorate of Environment and Public Works, (2007), Atmospheric pollution in Thessaloniki - 2006 (in Greek). Available at http://www.ypeka.gr/Default.aspx?tabid=490\&language=el-GR.

Samara C. et al., (1990), Characterization of airborne particulate matter in Thessaloniki, Greece. 1. Source related heavy-metal concentrations within TSP, Toxicological and Environmental Chemistry, 29, 107-119.

Samara C. et al., (2003), Chemical mass balance source apportionment of $\mathrm{PM}_{10}$ in an industrialized urban area of Northern Greece, Atmospheric Environment, 37, 41-54.

Samara C. and Voutsa D., (2005), Size distribution of airborne particulate matter and associated heavy metals in the roadside environment, Chemosphere, 59, 1197-1206.

Tsitouridou R. and Samara C., (1993), First results of acidic and alkaline constituents determination in air particulates of Thessaloniki, Greece, Atmospheric Environment Part B. Urban Atmosphere, 27, 313-319.

Vardoulakis S. and Kassomenos P., (2008), Sources and factors affecting $\mathrm{PM}_{10}$ levels in two European cities: Implications for local air quality management, Atmospheric Environment, 42, 3949-3963.

Vassilakos Ch. et al., (2005), Temporal variations of $\mathrm{PM}_{2.5}$ in the ambient air of a suburban site in Athens, Greece, Science of the Total Environment, 349, 223- 231.

Voutsa D. et al., (2002), Elemental composition of airborne particulate matter in the multi-impacted urban area of Thessaloniki, Greece, Atmospheric Environment, 36, 4453-4462.

Zikovsky L., Leduc R. and Badilo M., (1987), Comparison of measured distributions of concentrations of trace elements in air particulates with normal and lognormal probability functions, International Journal of Environmental Studies, 29, 175-179. 